Sharif University of Technology
Scientia Iranica
Transactions E: Industrial Engineering
http://scientiairanica.sharif.edu
IRAN ICA

Research Note

\title{
A new approach in the DEA technique for measurement of productivity of decision-making units through efficiency and effectiveness
}

\author{
J. Esmaeeli ${ }^{\mathrm{a}}$, M. Amiri ${ }^{\mathrm{b}, *}$, and H. Taghizadeh ${ }^{\mathrm{a}}$ \\ a. Department of Industrial Management, Faculty of Management and Economics and Accounting, Islamic Azad University, Tabriz \\ Branch, Tabriz, Iran. \\ b. Department of Industrial Management, Faculty of Management and Accounting, Allameh Tabataba'i University, 14348-63111 \\ Tehran, Iran.
}

Received 28 November 2019; received in revised form 25 December 2020; accepted 18 January 2021

\author{
KEYWORDS \\ Effectiveness; \\ Efficiency; \\ Productivity; \\ DEA; \\ Productivity indexes.
}

\begin{abstract}
So far, numerous studies have been developed to evaluate the performance of Decision-Making Units (DMUs) through Data Envelopment Analysis (DEA) technique in different places, but most of these studies have measured the performance of DMUs based on efficiency criteria. The productivity is considered as a key factor in the success and development of DMUs and its evaluation is more comprehensive than efficiency evaluation. Recently, the productivity has been considered in DEA technique. Productivity in these studies is often evaluated through the productivity indexes. These indexes require at least two time periods and, also, the two important elements of efficiency and effectiveness in these studies are not significantly evident. There are few studies that measure productivity through efficiency and effectiveness. These few researches also measure the efficiency and effectiveness in two stages separately. Thus, the purpose of this study is to develop a new approach in the DEA technique in order to measure productivity of DMUs through efficiency and effectiveness simultaneously, in one stage and interdependently. One case study demonstrates the application of the proposed approach in the branches of a Bank. The use of the proposed approach revealed that efficient branches are not necessarily productive, but productive branches are also efficient.
\end{abstract}

(C) 2023 Sharif University of Technology. All rights reserved.

\section{Introduction}

Nowadays, performance assessment for industrial and economical units plays an important role in achieving managerial success and continuous progress [1]. Vari-

*. Corresponding author. Tel.: +982126742356 E-mail addresses: ej.manager@gmail.com (J. Esmaeeli) amiri@atu.ac.ir (M.Amiri) taghizadeh@iaut.ac.ir (H. Taghizadeh)

doi: $10.24200 /$ sci.2020.54858.3961 ous criteria have been proposed as performance evaluation criteria of organizations. Efficiency, effectiveness, and productivity are the most important of these criteria [2]. Productivity is a combination of efficiency and effectiveness simultaneously; therefore, its evaluation will be more complete than the separate evaluation of effectiveness and efficiency [3]. Productivity is a subject of interest to many economists and policymakers and it is crucial to economic growth and survival [4]. Productivity is also considered an important element for the operations of the organization and its increase creates a competitive advantage for organization and is 
a vital issue for management. Making a profit, reducing costs, and developing an organization in the long term require productivity enhancement [5].

Data Envelopment Analysis (DEA) is one of the main techniques employed for analyzing the efficiency of organizations and is considered as a well-known, popular, and standard method for measuring the efficiency of manufacturing and service organizations [68]. According to many experts, researchers, and users of operations research, the advantages of DEA technique outweigh its disadvantages [9].

Recently, there are studies that have evaluated the productivity of Decision-Making Units (DMUs) through the DEA technique. These studies are divided into the following two categories:

I. Productivity evaluation through productivity indicators: In this type of evaluation, productivity is measured through indicators such as Malmquist productivity index and Luenberger productivity index. These indicators are the methods used for analyzing efficiency changes over a time period that have been applied in several fields $[10,11]$. In other words, these indicators show if the efficiency of a DMU has increased, decreased, or remained constant over a period [11]. Far (1994) first proposed the DEA-Malmquist Productivity Index to measure the growth of productivity and technical progress of DMUs [12]. The Malmquist productivity index is an indicator that shows the total factor productivity growth of a DMU, and it can analyze the efficiency changes between two time periods under multiple inputs and multiple outputs [13]. The Malmquist productivity index is a non-parametric function of evaluating the productivity with the ratio of the distance function and it has a ratio structure, while the Luenberger productivity index has an additive structure [14]. The Malmquist productivity index generally uses Russell measure or enhanced Russell measure of inefficiency, in which multiplication is used, but the Luenberger productivity index uses a slack-based measure of efficiency, in which the addition is used [15]. However, these indicators do not show all factors in a system [16]. These indexes also require at least two time periods to evaluate the productivity of DMUs and, also, the two important elements of efficiency and effectiveness in these studies are not significantly evident;

II. The productivity evaluation through efficiency and effectiveness: As it is known, DEA is mostly used to evaluate the efficiency of DMUs [17] regardless of effectiveness, while effectiveness is as important as efficiency for evaluating DMUs [3]. Many studies have developed organizational effectiveness models, but they have not used a suitable analytical tool to evaluate effectiveness [18]. There exist few researches that measure productivity through efficiency and effectiveness [5] and they measure efficiency and effectiveness in two stages. Efficiency and effectiveness are complementary and are not independent of each other but they have a different meaning [16]. Therefore, they must be measured in one stage, simultaneously and interdependently.

The publications related to DEA can be divided into two groups: The first group uses DEA to evaluate the performance of different organizations, while the second group develops an original model theoretically [19]. The present study takes the second route. According to the above information, the aim and innovation of the present study is to propose a new approach, namely the DEA technique, to measure the productivity of DMUs through efficiency and effectiveness in one stage, interdependently and simultaneously. The effectiveness is formulated in DEA technique to achieve this purpose. Using the proposed model, we can easily measure the productivity of DMUs through effectiveness and efficiency in one stage and at the same time. This proposed model has all the advantages of the original DEA technique, in addition to evaluating the effectiveness of DMUs along with efficiency. In a case study considered here, the productivity of Maskan bank branches in Gilan province was evaluated through efficiency and effectiveness, but it could be used in all organizations with similar inputs and outputs. After measuring the productivity of the branches, it becomes clear that although efficient branches are not necessarily productive, productive branches are efficient.

Figure 1 shows the main steps of solving the problem.

\section{Literature review}

In this section, first, the keywords of the research will be described and, then, previous studies related to the research topic will be presented. Finally, the gap between previous studies and the current study is explained.

\subsection{Efficiency, effectiveness, and productivity}

One of the key purposes of the organization is to improve performance, because according to Azar and Zaree [20], it leads to increased employee motivation, decision support, improvement of organizational learning, continuous improvement, and increased communication and coordination. Various criteria have been proposed as performance evaluation criteria for organizations in which efficiency, effectiveness, and productivity are the most important of these criteria [2].

The efficiency is defined in various terms such as increasing output, reducing costs, increasing profits, and "doing things right" [21]. This term is also defined as [5]: 


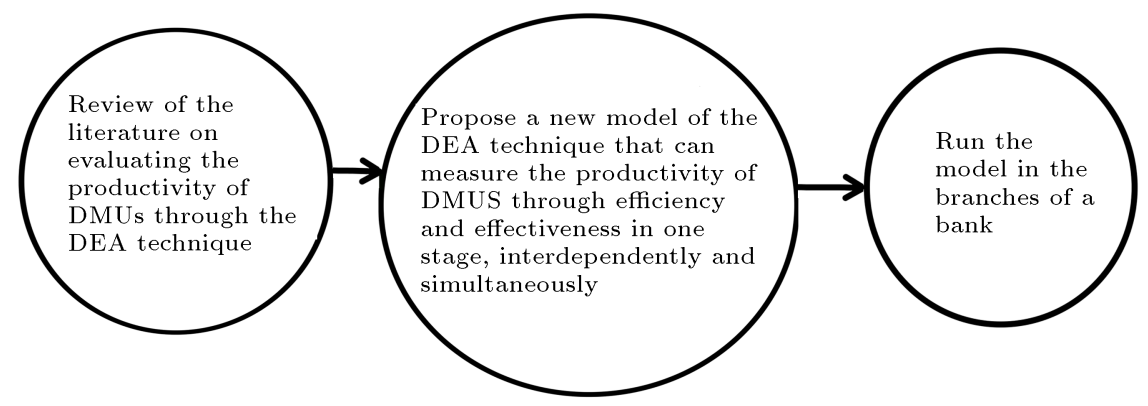

Figure 1. The main steps to solve the problem.

$$
\begin{aligned}
\text { efficiency } & =\frac{\text { actual consumption }}{\text { expected consumption }} \\
& =\frac{\text { produced output }}{\text { consumed } \text { input }}=\frac{\text { output }}{\text { input }} .
\end{aligned}
$$

The effectiveness is defined as choosing activities in the right way, being able to achieve predetermined goals and "doing the right thing" [5]. According to Lee and Johnson [16], the effectiveness is determined by the distance between observed outputs and a set of desired goals. Azadi et al. [3] also defined the effectiveness of a DMU as:

$$
\text { effectiveness }=\frac{\text { output }}{\text { goal }} \text {. }
$$

Roghanian et al. [5] defined productivity as a combination of efficiency and effectiveness as follows:

$$
\text { productivity }=\frac{\text { output }}{\text { input }}+\frac{\text { output }}{\text { goal }} \text {. }
$$

Moreover, Asia Productivity Organization (APO) defines the productivity as: "Productivity = Efficiency + Effectiveness $=$ Doing things right + Doing the right things" [5].

According to the information in this section, we find that the sum of efficiency and effectiveness is the productivity and the formula of efficiency and effectiveness can also be extracted from this section. Hence, we have:

$$
\text { productivity }=\frac{\text { output }}{\text { input }}+\frac{\text { output }}{\text { goal }} \text {. }
$$

\subsection{Relationships among efficiency, effectiveness, and productivity}

Efficiency is "doing the things right" according to definition; in the same way, effectiveness is defined as "doing the right things", and productivity is referred to the sum of efficiency and effectiveness and includes both of them. That is, the productivity includes measurement and assessment of return and outcome of an organization's activities against the goals and the spent resources [2]. Many studies have described the

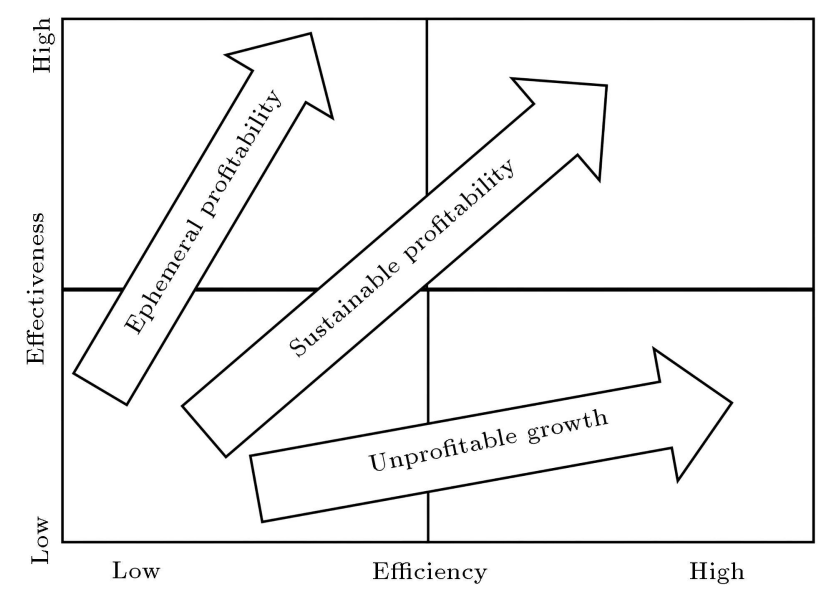

Figure 2. The effect of different levels of efficiency and effectiveness.

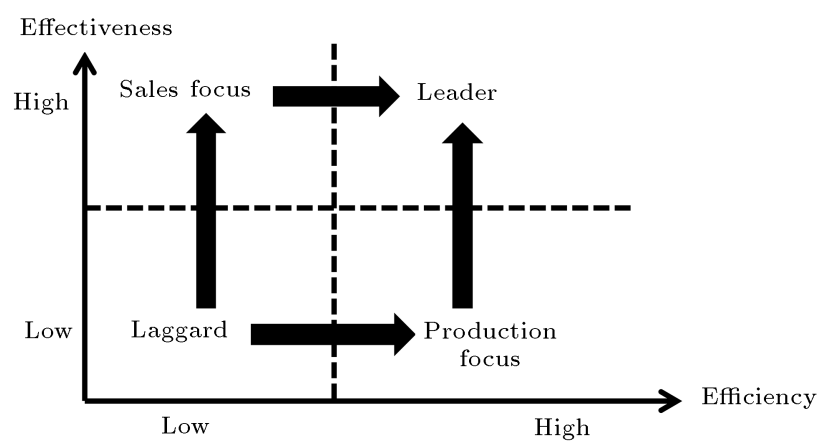

Figure 3. Two-dimensional strategic position between efficiency and effectiveness.

relationship among these three concepts in figures, the most important of which are mentioned below.

Azar et al. [22], Lee and Johnson [16], and Roghanian et al. [5] drew Figures 2, 3, and 4, respectively. Looking closely, we find that all three figures are composed of two-dimensional matrices, and only in each one are the titles in the matrix cells different from one another. In other words, each of these studies considers the relationship between efficiency and effectiveness from different perspectives. The fourth cell of each matrix indicates the high efficiency and effectiveness (productivity) of an organization, and the other cells 


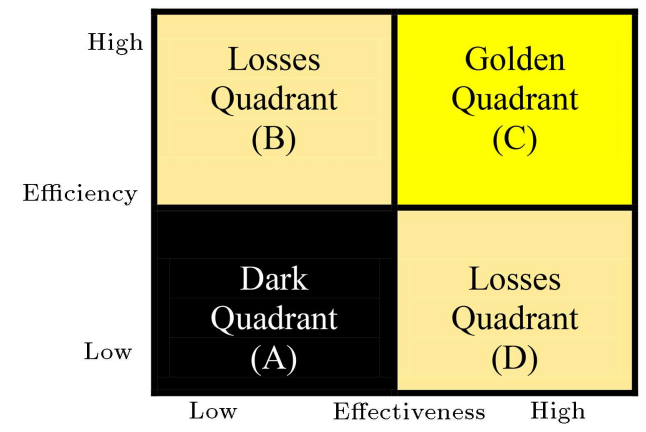

Figure 4. Efficiency and effectiveness matrix.

indicate that the organization experiences weakness in one or both of them (unproductively). In Figure 2, the relationship between efficiency and effectiveness is profit-oriented. The fourth cell of this matrix indicates that high efficiency and effectiveness lead to longterm and sustainable profitability. The rest of the matrix cells are weak in profitability. In Figure 3, the relationship between efficiency and effectiveness is strategic-oriented, meaning that the organization has a specific strategy for each of the matrix cells. The fourth cell of this matrix shows that the organization is the leader in the strategy of developing new markets and innovation due to its high efficiency and effectiveness. In other words, the organization is optimal in choosing its production and sales strategies, leading to competitive advantage. The organization is weak in terms of production or sales strategies in the rest of the matrix cells. In Figure 4, the mentioned relationship is customer-oriented, meaning that the organization is moving toward customer satisfaction. In the fourth cell of this matrix, the organization with minimum resources brings about maximum customer satisfaction. The organization performs poorly in the rest of the matrix cells in terms of customer service or resource consumption.

According to the above information, we can set the relationship between efficiency and effectiveness and productivity as Figure 5 [22].

If we analyze the information presented in this section, it becomes clear that to evaluate productivity through efficiency and effectiveness, it is necessary that efficiency and effectiveness be considered interdependently and evaluated simultaneously and in one stage. Moreover, efficiency and effectiveness are two integral components of productivity and it is better to use these two components to evaluate productivity.

\subsection{Data Envelopment Analysis (DEA)}

Farrell [23] introduced nonparametric methods for estimating efficiency for the first time. There was an input and an output in his case to measure efficiency. Charnes et al. [24] developed the Farrell view and provided a fractional and nonlinear mathematical programming model to measure efficiency

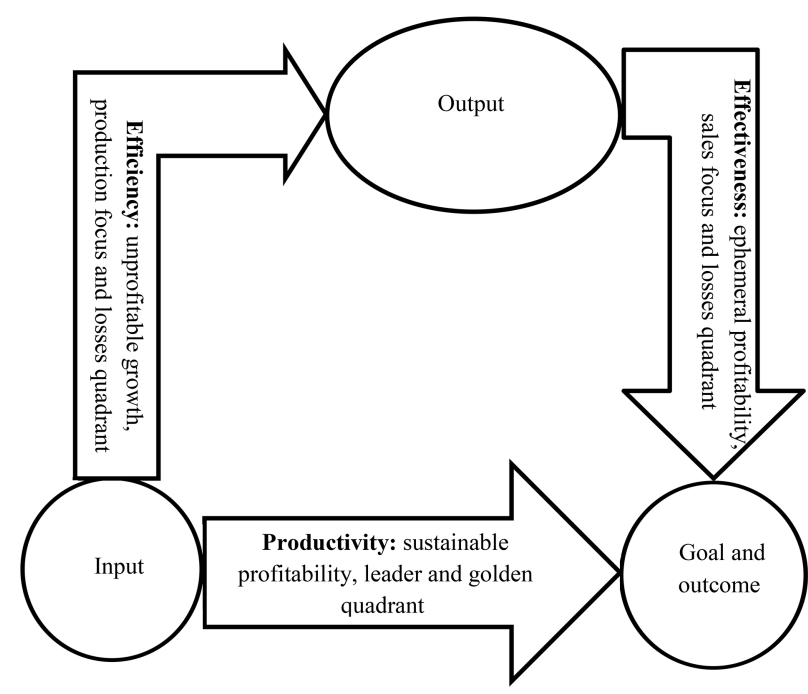

Figure 5. The relationship among effectiveness, efficiency, and productivity.

with multiple inputs and outputs. This model is called DEA model and then, the model was named Charnese, Coopere and Rhodes (CCR) model after the initials of the developers' name. Banker et al. [25] presented a new model named Bankere, Charnese and Cooper (BCC) model, with a minor change in the CCR model. Accordingly, the DEA is a boundarybased nonparametric evaluation model that is used to measure the relative efficiency and performance of a set of comparable entities, called DMUs, and to convert inputs into outputs [26]. The performance of a DMU is calculated by comparing its efficiency with the best observed performance in the data set. This linear programming model determines optimal weights for inputs and outputs needed to maximize the efficiency [27]. The basic DEA models are faced with two assumptions: Constant Return to Scale (CRS) and Variable Return to Scale (VRS); the former is called the CCR model while the latter assumption is called the BBC model [28]. The CCR model measures the technical efficiency of DMUs [29] and is used when the units operate at their optimal size [28]. The BCC model calculates the pure technical efficiency [29] and is used when the units do not operate under optimal size conditions [28]. Cadavid et al. [29] described the relationship between technical efficiency (CCR) and pure technical efficiency (BCC) through the following:

Scale efficiency $=\frac{\mathrm{CCR} \text { efficiency }}{\mathrm{BCC} \text { efficiency }}$,

$\mathrm{CCR}$ efficiency $=\mathrm{BCC}$ efficiency $\times$ scale efficiency.

In another classification, the CCR and BCC models are called radial models, and the non-radial models include additive model, multiplicative model, Range-Adjusted Measure (RAM), and Slack-Based Measure (SBM) [30]. Advantages of DEA are as follows: 
1. It does not need to define the mathematical form of the production function;

2. It is useful to discover relationships that are otherwise impossible for other methods;

3. It can handle multiple inputs and outputs;

4. It can be used for any input-output measurement;

5. In this technique, resources that are inefficient in each DMU can be identified and analyzed [31];

6. It avoids the effect of subjective factors on the evaluation results [32];

7. In this method, inputs and outputs can have different units of measurement such as quantitative and qualitative [33];

8. DEA application is easy and interpretable [7].

Clermont and Schaefer [9] state that "from the viewpoint of many researchers and users in the field of Operations Research, the advantages of DEA seem to outweigh the disadvantages".

According to the information in this section, the reasons for using the DEA technique in this study to evaluate the performance of DMUs is identified and also the concepts described in this section can be used in Section 3.

\subsection{Related works}

In this section, a number of previous studies on the productivity of DMUs through the DEA are reviewed.

Kao and Liu [8] proposed a model based on the Network DEA (NDEA) approach to measure the overall efficiency of DMUs in a multi-period system, taking into account the operations in each period. The overall efficiency of 22 commercial banks has been measured through this model and, also, the Malmquist productivity index technique has been used to measure the efficiency changes between the two periods. Fujii et al. [34] applied a new methodology using the weighted Russell directional distance model to measure technical inefficiency while they employed Malmquist productivity index-DEA and Luenberger productivity index-DEA models to evaluate productivity growth of the banking industry over the period of "2004 to 2011". The results show that the levels of inefficiency are significantly different among the three ownership structures of banks in India. Using Malmquist productivity index-DEA method, Salarieh et al. [35] investigated the effects of efficiency changes and technology on productivity growth of Iran's agricultural sector in the 2004 - 2013 period. The results show that efficiency changes play a dominant role in productivity growth and the share of technology changes is small. Falavigna et al. [10] applied two-stage analysis by Simar and Wilson (2007) and the Malmquist productivity indexDEA method in order to better understand the impact of a specific policy on the productivity of the Italian tax judiciary. The results of this study show that judging is a human-centered activity and although their careful organization is necessary for the efficiency of the courts, the role of judges is still vital. Yang et al. [32] surveyed the inefficiency and productivity of 64 Chinese universities from 2010 to 2013 using a general two-stage network directional distance framework with carry-over variable to evaluate the inefficiency of universities and a Luenberger productivity index-DEA model to measure productivity changes over time. The results showed that the Luenberger productivity index of universities increased significantly over time. Sadeghi et al. [36] evaluated the performance of private banks in Iran via DEA. In this study, using DEA approach, a twostage model was designed to measure the efficiency and effectiveness of banks during different time periods. Using this model, the efficiency and effectiveness scores of each bank in each time period are obtained. The results show that fully efficient or fully efficient banks in a period are not necessarily the best banks in terms of performance in that period. Fujii et al. [37], in the first stage, evaluated the bank efficiency and productivity changes in EU28 countries using weighted Russell directional distance and Malmquist productivity indexDEA models and in the second stage, with a disaggregated approach, they analyzed the contribution of individual bank inputs in its efficiency and productivity growth and, in the third stage, tested the convergence of EU28 Bank productivity with the inefficiency of individual bank inputs. They found no evidence of group convergence for bank productivity, but only evidence of convergence in changing bank efficiency and technical change. Using DEA and Malmquist productivity index and log-linear learning models, Aduba and Asgari [4] empirically estimated the productivity and technological learning of manufacturing industries. The result shows negative total factor productivity growth between 2000 and 2014. Li et al. [14] used the Malmquist productivity index-DEA model to evaluate China's total factor productivity between 1978 and 2016 under resource and environmental constraints. The results showed that under conditions of resource and environmental constraints, China's total factor productivity was slow in growth. Song et al. [13] used the Malmquist productivity index-DEA model to evaluate the scientific productivity of Chinese universities. The results show that due to technological progress, the productivity of Chinese universities has increased significantly between 2009 and 2016 .

It can be seen that the above studies measure the productivity of DMUs through productivity indicators such as Malmquist productivity index and Luenberger productivity index, or that they evaluate the productivity of DMUs through efficiency and effectiveness in two stages. For the reasons presented in subsection 
2.2 , those studies that measure productivity through efficiency and effectiveness have more advantages than studies that measure productivity through productivity indicators. In addition, studies based on productivity indicators require at least two time periods. Studies that measure productivity through efficiency and effectiveness are two-stage based. Therefore, as mentioned in the introduction, we seek an approach that measures the productivity of decision units through efficiency and effectiveness in one stage and in a period, simultaneously and interdependently.

\section{Proposed approach}

Based on Section 2.3, the CCR model presented by Charnes et al. [24] is given in Relation (1):

$$
\begin{aligned}
& \operatorname{Max} E_{0}=\frac{\sum_{r=1}^{s} u_{r} Y_{r 0}}{\sum_{i=1}^{m} v_{i} X_{i 0}}, \\
& \text { s.t. : } \quad \frac{\sum_{r=1}^{s} u_{r} Y_{r j}}{\sum_{i=1}^{m} v_{i} X_{i j}} \leq 1, \quad j=1,2, \ldots, n, \\
& u_{r}, v_{i} \geq \varepsilon, \quad r=1,2, \ldots, s ; \quad i=1,2, \ldots, m .
\end{aligned}
$$

Consider $n \mathrm{DMU}_{\mathrm{s}}(j=1,2, \cdots, n)$ under assessment. Each DMU consumes $m$ inputs $(i=1,2, \cdots, m)$ and produces $s$ outputs $(r=1,2, \cdots, s)$ denoted by $X_{1 j}, X_{2 j}, \cdots, X_{m j}$ and $Y_{1 j}, Y_{2 j}, \cdots Y_{s j}$, respectively. The objective function $E_{k}$ is maximized for every $D M U_{0}$ individually, where $X_{i k}$ and $Y_{r k}$ are the $i$ th input and $r$ th output of $D M U_{0}$, respectively; $u_{r}$ and $v_{i}$ are the weights of the outputs and inputs, respectively, and $\varepsilon$ is a small non-Archimedean number for restricting the DMU to assign 0 weight to unfavorable factors [38].

However, Relation (1) only measures the efficiency of DMUs. In order to be able to measure the productivity of DMUs through efficiency and effectiveness, it is necessary to formulate effectiveness in Relation (1). As discussed in Section 2.1, we can define effectiveness as follows:

$$
\text { effectiveness }=\frac{\text { outputs }}{\text { goals }} \text {. }
$$

We define the effectiveness of a DMU as the ratio of the output to the predetermined goal as follows:

$$
\begin{aligned}
& \text { effectiveness of } \mathrm{DMU}_{0}= \\
& \frac{\text { weighted outputs of } \mathrm{DMU}}{\text { weighted standard outputs (goals) of } \mathrm{DMU}}
\end{aligned}
$$

$$
=\frac{\sum_{r=1}^{r k} u_{r} Y_{r 0}}{\sum_{r=1}^{r k} \eta_{r} g_{r 0}}
$$

where equation $\eta_{r} g_{r 0}$ is the weighted standard output (goals) of $\mathrm{DMU}_{0}$.

As discussed in Sections 2.1 and 2.2, productivity is the sum of efficiency and effectiveness; then, Relation (2) is incorporated in Relation (3) as follows:

$$
\begin{aligned}
& \operatorname{Max} p_{0}=\frac{\sum_{r=1}^{r k} u_{r} Y_{r 0}}{\sum_{i=1}^{m k} v_{i} x_{i 0}}+\frac{\sum_{r=1}^{r k} u_{r} Y_{r 0}}{\sum_{r=1}^{r k} \eta_{r} g_{r 0}}, \\
& \text { s.t. : } \frac{\sum_{r=1}^{r k} u_{r} Y_{r j}}{\sum_{i=1}^{m k} v_{i} x_{i j}} \leq 1, \quad j=1,2, \ldots, n \\
& \frac{\sum_{r=1}^{r k} u_{r} Y_{r j}}{\sum_{r=1}^{r k} \eta_{r} g_{r j}} \leq 1, \quad j=1,2, \ldots, n, \\
& u_{r}, v_{i}, \eta_{r} \geq \varepsilon, \quad r=1,2, \ldots, r k ; \quad i=1,2, \ldots, m k .
\end{aligned}
$$

Relation (3) is nonlinear and can be linearized. To ensure the solvability, two extra constraints are added for $D M U_{0}$ to transform the fractional DEA model into a linear programming model [39]. The proposed model can then be solved by LINGO software. So, we have:

$$
\begin{aligned}
& \operatorname{Max} P_{0}=\sum_{r=1}^{r k} u_{r} Y_{r 0}+\sum_{r=1}^{r k} U_{r} Y_{r 0}, \\
& \text { s.t. } \quad \sum_{i=1}^{m k} v_{i} x_{i 0}=1, \\
& \sum_{r=1}^{r k} \eta_{r} g_{r 0}=1 \\
& \sum_{r=1}^{r k} u_{r} Y_{r j}-\sum_{i=1}^{m k} v_{i} x_{i j} \leq 0, \quad j=1,2, \ldots, n, \\
& \sum_{r=1}^{r k} U_{r} Y_{r j}-\sum_{r=1}^{r k} \eta_{r} g_{r j} \leq 0, \quad j=1,2, \ldots, n, \\
& u_{r}, v_{i}, \eta_{r} \geq \varepsilon, \quad r=1,2, \ldots, r k ; \quad i=1,2, \ldots, m k .
\end{aligned}
$$

As the contribution of this study, Relation (4) says if $p_{0}$ is equal to 2 , then the DMU is productive and 
if it is less than 2, it is non-productive. The DMU may be efficient but not productive; however, if the DMU is productive, it will certainly be efficient. Using Relation (4), we can measure productivity of DMUs through effectiveness and efficiency easily in one stage and in a period, simultaneously and interdependently. Therefore, the purpose of the research is met through Relation (4).

\section{Case study}

This section presents an experimental study on the bank branches. The banking plays the role of mediator between the net savers and net borrowers. Banks deal with people's most liquid asset and run the country's economy [31]. The efficiency and quality of services provided by banks not only have a significant impact on economic growth but also play a very important role in the daily life of each individual [40]. Therefore, analyzing the performance of banking industry and identifying techniques for evaluating it have become the focus of managers, policymakers, economists, institutions, and academic research $[7,41]$.

Examining the literature on evaluating the performance of the banking industry, we find that there are several methods for this purpose, such as financial ratio analysis, regression analysis, and frontier efficiency analysis [42]. The analysis of financial ratios such as return on assets, loans to assets, loans per employee, deposits per employee, and cost to income [43] and the regression analysis have a significant impact on many business areas, but they have limitations that make them unsuitable for evaluating the performance of bank branches. Some limitations of these methods are: failure to use multiple inputs and outputs in each evaluation, the need for a special function to identify different aspects of bank branch operations, and the inability to consider all variables $[42,44]$ (for further information on the limitations of these methods, see [42-44]). The frontier efficiency method evaluates the performance of the branch in comparison with the best branch in terms of performance. One of the methodologies for this method is DEA [42]. Referring to the advantages of the DEA technique in Section 2.3, it can be stated that this technique does not have the limitations of the previous two methods. Also, this method has been successfully used to evaluate the performance of banks and numerous studies have been conducted on measuring the performance of banks by this method $[44,45]$. Another reason to use DEA in evaluating the performance of banks is that can adapt to small sample sizes and application of categorical variables that are commonly used in country-specific panels of data. In addition, this advantage is especially important for banking datasets that are small in nature $[7,46]$.

The choice of inputs and outputs is perhaps the

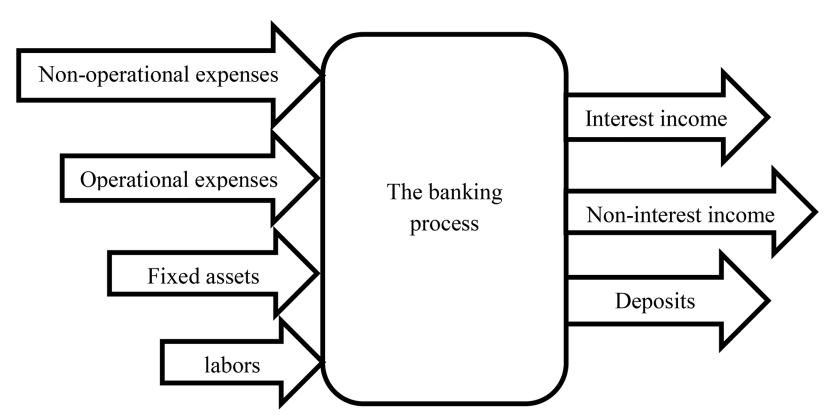

Figure 6. Network process for banking industry performance evaluation.

most important task in employing DEA to measure the efficiency and productivity of DMUs [47]. Banks are considered financial institutions that transform labors, fixed assets, non-operational expenses, and operational expenses into deposits, interest income, and non-interest income. Fixed assets include materials, space, and equipment in this approach. Nonoperational expenses include personnel expenses, general and administrative expenses, and awards and promotions. Operational expenses include interest expenses. Interest incomes are part of the bank's income, which is derived from contributions from individuals. Non-interest incomes are another category of bank incomes earned through service fees and financial and investment advisories. These incomes include credit card services, bank guarantee services, electronic banking services, exchange services, letter of credits service, maintenance fees for clients' documents and securities, and issuing various types of checks. The performance process in the banking industry is shown in Figure 6 [48].

The research data related to Maskan Bank Branches by Zarei Mahmoudabadi [48] are provided in Table 1. The data were non-scaled using the norm $n_{i j}=\frac{a_{i j}}{\sum^{a_{i j}}}$ [49]. The columns related to the goals indicate that each output earned through interviews and surveys from bank managers. In other words, these columns indicate the standard output (goal) against the actual output to evaluate effectiveness.

\subsection{The efficiency evaluation results for bank branches using DEA model (Relation (1)):}

Relation (1) is used in this section to evaluate the efficiency of bank branches. Using lingo software, the results of this evaluation are provided in Table 2 . The DMUs $_{\mathrm{s}} 1,2,3,4,6,8,10,11,12,13,14,15,16$ are known as efficient DMUs according to the results presented in Table 2.

\subsection{The productivity evaluation results for bank branches using the proposed model (Relation (4)):}

The productivity of the bank branches is evaluated by 
Table 1. The performance evaluation data of bank branches.

\begin{tabular}{|c|c|c|c|c|c|c|c|c|c|c|}
\hline \multirow[b]{2}{*}{ DMUs } & \multicolumn{4}{|c|}{ Inputs } & \multicolumn{6}{|c|}{ Outputs } \\
\hline & Input 1 & Input 2 & Input 3 & Input 4 & Output 1 & Goal 1 & Output 2 & Goal 2 & Output 3 & Goal 3 \\
\hline 1 & 0.0543 & 0.0476 & 0.0764 & 0.0403 & 0.0445 & 0.0500 & 0.1038 & 0.1000 & 0.0405 & 0.0400 \\
\hline 2 & 0.0870 & 0.0878 & 0.0905 & 0.1159 & 0.0806 & 0.0800 & 0.1331 & 0.1000 & 0.1219 & 0.1000 \\
\hline 3 & 0.0543 & 0.0770 & 0.0762 & 0.1028 & 0.0719 & 0.0700 & 0.0918 & 0.1000 & 0.0999 & 0.1000 \\
\hline 4 & 0.0652 & 0.0338 & 0.0534 & 0.0511 & 0.0330 & 0.0300 & 0.0536 & 0.0600 & 0.0480 & 0.0400 \\
\hline 5 & 0.0435 & 0.0502 & 0.0475 & 0.0511 & 0.0523 & 0.0500 & 0.0367 & 0.0400 & 0.0511 & 0.0500 \\
\hline 6 & 0.0435 & 0.0400 & 0.0459 & 0.0233 & 0.0430 & 0.0400 & 0.0264 & 0.0300 & 0.0244 & 0.0300 \\
\hline 7 & 0.0543 & 0.0361 & 0.0422 & 0.0343 & 0.0370 & 0.0400 & 0.0432 & 0.0400 & 0.0361 & 0.0400 \\
\hline 8 & 0.0543 & 0.1069 & 0.0628 & 0.0812 & 0.1006 & 0.1000 & 0.0605 & 0.0600 & 0.0674 & 0.0700 \\
\hline 9 & 0.0652 & 0.0494 & 0.0601 & 0.0537 & 0.0489 & 0.0500 & 0.0448 & 0.0500 & 0.0552 & 0.0600 \\
\hline 10 & 0.0543 & 0.0811 & 0.0593 & 0.0652 & 0.0863 & 0.0900 & 0.0511 & 0.0500 & 0.0624 & 0.0600 \\
\hline 11 & 0.0652 & 0.0457 & 0.0610 & 0.0640 & 0.0451 & 0.0500 & 0.0456 & 0.0500 & 0.0647 & 0.0700 \\
\hline 12 & 0.0435 & 0.0320 & 0.0344 & 0.0342 & 0.0347 & 0.0300 & 0.0382 & 0.0400 & 0.0352 & 0.0400 \\
\hline 13 & 0.0543 & 0.0466 & 0.0461 & 0.0411 & 0.0435 & 0.0400 & 0.0677 & 0.0700 & 0.0480 & 0.0500 \\
\hline 14 & 0.0652 & 0.0719 & 0.0531 & 0.0601 & 0.0805 & 0.0800 & 0.0590 & 0.0600 & 0.0568 & 0.0500 \\
\hline 15 & 0.0435 & 0.0335 & 0.0411 & 0.0319 & 0.0384 & 0.0400 & 0.0296 & 0.0300 & 0.0349 & 0.0400 \\
\hline 16 & 0.0543 & 0.0498 & 0.0488 & 0.0545 & 0.0488 & 0.0500 & 0.0395 & 0.0400 & 0.0597 & 0.0600 \\
\hline 17 & 0.0435 & 0.0422 & 0.0395 & 0.0407 & 0.0400 & 0.0400 & 0.0366 & 0.0400 & 0.0438 & 0.0500 \\
\hline 18 & 0.0543 & 0.0683 & 0.0572 & 0.0547 & 0.0709 & 0.0700 & 0.0388 & 0.0400 & 0.0499 & 0.0500 \\
\hline
\end{tabular}

Table 2. The efficiency evaluation results of bank branches using DEA approach (Relation (2))

\begin{tabular}{ccc}
\hline DMUs & Efficiency & Rank \\
\hline 1 & 1 & 1 \\
2 & 1 & 1 \\
3 & $\mathbf{1}$ & 1 \\
4 & 1 & 1 \\
5 & 0.9986 & 14 \\
6 & 1 & 1 \\
7 & 0.9701 & 16 \\
8 & 1 & 1 \\
9 & 0.9508 & 18 \\
10 & 1 & 1 \\
11 & $\mathbf{1}$ & 1 \\
12 & 1 & 1 \\
13 & 1 & 1 \\
14 & 1 & 1 \\
15 & $\mathbf{1}$ & 1 \\
16 & 1 & 1 \\
17 & 0.9806 & 15 \\
18 & 0.9548 & 17 \\
\hline
\end{tabular}

Relation (4) in this section. Using lingo software, the evaluation results are provided in Table 3.

It can be observed that DMUs $1,2,4,6,8,10$, $12,13,14,16$ are productive units in Table 3 . Figure 7 shows that units 3,11 , and 15 are efficient, but not productive. Moreover, the ranking of some units in terms of efficiency and productivity is not the same.
Table 3. The productivity evaluation results of bank branches by the proposed model (Relation (4)).

\begin{tabular}{ccc}
\hline DMUs & Productivity & Rank \\
\hline 1 & 2 & 1 \\
2 & 2 & 1 \\
3 & $\mathbf{1 . 9 7 1 2}$ & 12 \\
4 & 2 & 1 \\
5 & 1.9986 & 11 \\
6 & 2 & 1 \\
7 & 1.8726 & 18 \\
8 & 2 & 1 \\
9 & 1.8823 & 17 \\
10 & 2 & 1 \\
11 & $\mathbf{1 . 9 6 5 3}$ & 13 \\
12 & 2 & 1 \\
13 & 2 & 1 \\
14 & 2 & 1 \\
15 & $\mathbf{1 . 9 3 8 7}$ & 15 \\
16 & 2 & 1 \\
17 & 1.9248 & 16 \\
18 & 1.9548 & 14 \\
\hline
\end{tabular}

Accordingly, the purpose of this study is to propose a DEA model in order to easily measure the productivity of DMUs through efficiency and effectiveness in one stage within a period of time, simultaneously and interdependently.

\section{Conclusions and suggestions}

As mentioned in the previous sections, nowadays, 


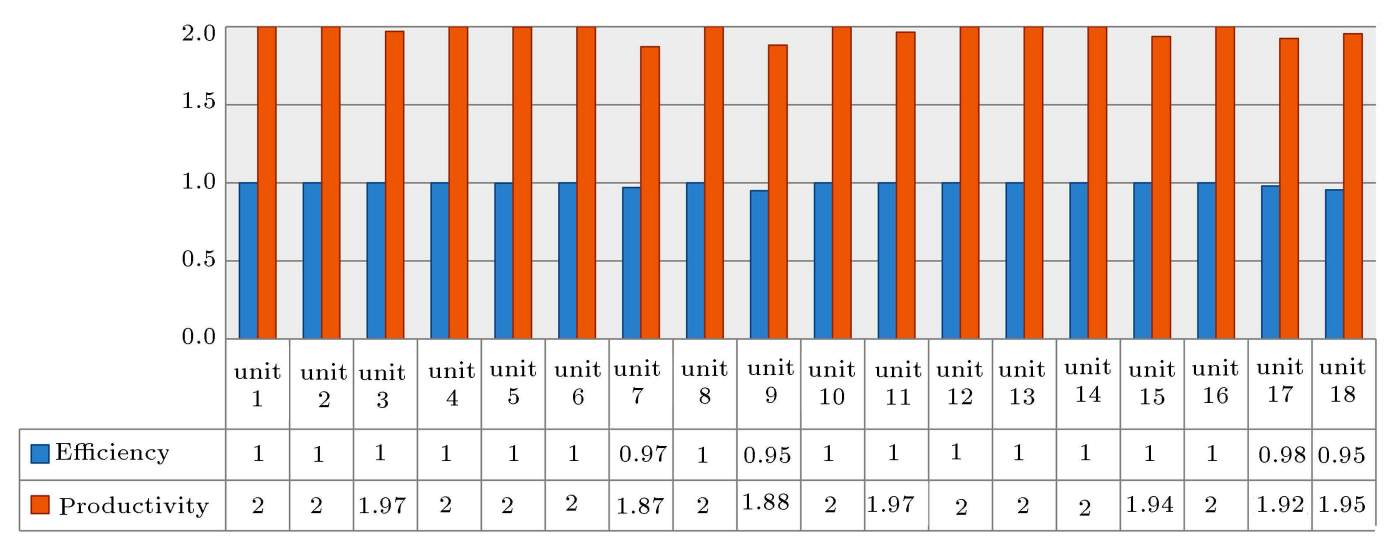

Figure 7. Efficiency and productivity of units.

performance assessment for industrial and economical units plays an important role in achieving managerial success and continuous progress. Productivity is enumerated as a significant factor in analyzing, monitoring, and supervising the performance and there is a consensus among scholars that the productivity management is an important component in continuous improvement and successful management.

In the literature, there were several methods used to measure productivity of Decision-Making Units (DMUs) in which one of these methods was Data Envelopment Analysis (DEA) technique. As mentioned in the previous sections, the DEA technique has many advantages and for these reasons, we chose this technique to evaluate productivity. After reviewing the literature on evaluating the productivity of Decision-Making Units (DMUs) through Data Envelopment Analysis (DEA), we found that a few studies have been done on this subject and they were divided into two categories:

1. Evaluating the productivity of DMUs through productivity indicators;

2. Evaluating the productivity of DMUs through efficiency and effectiveness.

Then, it was found that the studies related to the first case required at least two time periods to evaluate the productivity of DMUs and, also, the two important elements of efficiency and effectiveness in these studies were not significantly evident. Studies related to the second case were very few and they measured the efficiency and effectiveness of DMUs in two separate stages, while these two elements should be evaluated independently and in one stage. Therefore, a new DEA approach was proposed in this study to evaluate the productivity of DMUs through efficiency and effectiveness. This approach can measure the productivity of DMUs through efficiency and effectiveness simply, simultaneously, and in one stage. In addition, efficiency and effectiveness are evaluated in this approach interdependently.
A case study was presented to analyze this approach and the results of this case study can be listed as follows: The branches $1,2,3,4,6,8,10,11,12$, $13,14,15,16$ were considered as efficient branches according to the results presented in Table 2 using Relation (1). Branches 1, 2, 4, 6, 8, 10, 12, 13, 14, 16 were productive units in Table 3 using Relation (4). Considering Chart 4, we find that Branches 3, 11 , and 15 are efficient but not productive; however, any branch that is productive is also efficient. In other words, it is possible that the most efficient branch is not necessarily the most productive one, and this is because of the effectiveness formula included in the calculations. Therefore, the present study with a new approach in DEA technique can measure the productivity of all organizations that have similar inputs and outputs in a simple and understandable way.

Some suggestions for future research based on the results of this research include:

- Considering that the proposed approach in this study is based on the CCR approach, it can also be implemented using the BCC approach;

- The model parameters are all quantitative and precise, which can be considered as qualitative and imprecise in case of using fuzzy approach;

- The proposed approach can be used in network DEA models.

\section{References}

1. Kianfar, K., Ahadzadeh Namin, M., Alam Tabriz, A., et al. "Performance evaluation of banking organizations using the New Proposed Integrated DEA-BSC Model", Journal of Modern Processes in Manufacturing and Production, 8(1), pp. 73-90 (2019).

2. Azar, A., Valipour khatir, M., Moghbel Baerz, A., et al. "Evaluation of hospital efficiency by data envelopment analysis: Tehran University of Medical Sciences: 2009-2011", Journal of Health Administration, 16(53), pp. 36-46 (2013). 
3. Azadi, M., Jafarian, M., Farzipoor Saen, R., et al. "A new fuzzy DEA model for evaluation of efficiency and effectiveness of suppliers in sustainable supply chain management context", Computers \& Operations Research, 54, pp. 274-285 (2015).

4. Aduba, J.J. and Asgari, B. "Productivity and technological progress of the Japanese manufacturing industries 2000-2014: estimation with data envelopment analysis and log-linear learning model", Asia-Pacific Journal of Regional Science, 4(2), pp. 343-387 (2020).

5. Roghanian, P., Rasli, A., and Gheysari, H. "Productivity through effectiveness and efficiency in the banking industry", Procedia - Social and Behavioral Sciences, 40, pp. 550-556 (2012).

6. Zelenyuk, V. "Aggregation of inputs and outputs prior to data envelopment analysis under big data", European Journal of Operational Research, 282(1), pp. 172-187 (2020).

7. Fernandes, F.D.S., Stasinakis, C., and Bardarova, V. "Two-stage DEA-Truncated regression: application in banking efficiency and financial development", Expert Systems with Applications, 96, pp. 284-301 (2018).

8. Kao, C. and Liu, S-T. "Multi-period efficiency measurement in data envelopment analysis: The case of Taiwanese commercial banks", Omega, 47, pp. 90-98 (2014).

9. Clermont, M. and Schaefer, J. "Identification of outliers in data envelopment analysis", Schmalenbach Business Review, 71(4), pp. 475-496 (2019).

10. Falavigna, G., Ippoliti, R., and Ramello, G.B. "DEAbased Malmquist productivity indexes for understanding courts reform", Socio-Economic Planning Sciences, 62, pp. 31-43 (2018).

11. Gandhi Aradhana, V. and Sharma, D. "Technical efficiency of private sector hospitals in India using data envelopment analysis", Benchmarking: An International Journal, 25(9), pp. 3570-3591 (2018).

12. Wang, Z. and Feng, C. "Sources of production inefficiency and productivity growth in China: A global data envelopment analysis", Energy Economics, 49, pp. 380-389 (2015).

13. Song, Y., Schubert, T., Liu, H., et al. "Measuring scientific productivity in China using malmquist productivity index", Journal of Data and Information Science, 4(1), pp. 32-59 (2019).

14. Li, T., Huang, Z., and Drakeford, B.M. "Statistical measurement of total factor productivity under resource and environmental constraints", National Accounting Review, 1(1), pp. 16-27 (2019).

15. Wang, K. and Wei, Y-M. "Sources of energy productivity change in China during 1997-2012: A decomposition analysis based on the Luenberger productivity indicator", Energy Economics, 54, pp. 50-59 (2016).

16. Lee, C-Y. and Johnson, A.-L. "Effective production: measuring of the sales effect using data envelopment analysis", Annals of Operations Research, 235(1), pp. 453-486 (2015).
17. Kao, H-Y., Chan, C-Y., and Wu, D-J. "A multiobjective programming method for solving network DEA", Applied Soft Computing, 24, pp. 406-413 (2014).

18. Asmild, M., Paradi, J.C., Reese, D.N., et al. "Measuring overall efficiency and effectiveness using DEA", European Journal of Operational Research, 178(1), pp. 305-321 (2007).

19. Budimir, D., Sostaric, M.-I., and Vidovic, K. "Data envelopment analysis for determining the efficiency of variant solutions for traffic flow organization", PrometTraffic \& Transportation, 31(3), pp. 341-353 (2019).

20. Azar, A. and Zaree, M. "Improving performance evaluation and resolution measurement in DEA models by presenting a new model of CSW", Journal of Management Improvement, 7(2), pp. 99-114 (2013).

21. Nisar Khan, M., Ahmad, A., and Jehan, N. "Pakistani firms' efficiency: An empirical study of pakistani listed firms through data envelopment analysis", Global Social Sciences Review (GSSR), 3(3), pp. 158-174 (2018).

22. Azar, A., Zaree, M., Moghbel Baerz, A., et al. "Evaluating the productivity of a bank's branches using network data envelopment analysis approach (case study: A bank in Gilan province)", Journal of Monetary and Banking Research, 7(20), pp. 285-305 (2014).

23. Farrell, M.J. "The measurement of productive efficiency", Journal of the Royal Statistical Society, 120(3), pp. 253-281 (1957).

24. Charnes, A., Cooper, W.W., and Rhodes, E. "Measuring the efficiency of decision making units", European Journal of Operational Research, 2(6), pp. 429-444 (1978).

25. Banker, R.D., Charnes, A., and Cooper, W.W. "Some models for estimating technical and scale inefficiencies in data envelopment analysis", Management Science, 30(9), pp. 1078-1092 (1984).

26. Alamtabriz, A. and Imanipour, M. "Measuring the relative efficiency of health care offered in hospitals of Shahid Beheshti university of medical sciences using data envelopment analysis (DEA) technique", Health Information Management Journal, 8(3), pp. 315-325 (2011).

27. Stolzer, A.J., Friend, M.A., Truong, D., et al. "Measuring and evaluating safety management system effectiveness using Data Envelopment Analysis", Safety Science, 104, pp. 55-69 (2018).

28. Kocisova, K. and Paleckova, I. "The super-efficiency model and its use for ranking and identification of outliers", Acta Universitatis Agriculturae et Silviculturae Mendelianae Brunensis, 65(4) , pp. 1371-1382 (2017).

29. Visbal-Cadavid, D., Martinez-Gomez, M., and Guijarro, F. "Assessing the efficiency of public universities through DEA: A case study", Sustainability, 9, pp. 14-16 (2017). 
30. Tavassoli, M., Faramarzi, G.R., and Farzipoor Saen, R. "Efficiency and effectiveness in airline performance using a SBM-NDEA model in the presence of shared input", Journal of Air Transport Management, 34, pp. 146-153 (2014).

31. Kumar, N. and Singh, A. "Efficiency analysis of banks using DEA: A review", International Journal of Advance Research and Innovation, 1, pp. 120-126 (2014).

32. Yang, G., Fukuyama, H., and Song, Y. "Measuring the inefficiency of Chinese research universities based on a two-stage network DEA model", Journal of Informetrics, 12(1), pp. 10-30 (2018).

33. Noulas Athanasios, G., Glaveli, N., and Kiriakopoulos, I. "Investigating cost efficiency in the branch network of a Greek bank: an empirical study", Managerial Finance, 34(3), pp. 160-171 (2008).

34. Fujii, H., Managi, S., and Matousek, R. "Indian bank efficiency and productivity changes with undesirable outputs: A disaggregated approach", Journal of Banking \& Finance, 38, pp. 41-50 (2014).

35. Salarieh, M., Mohamadi Nejad, A., and Moghaddasi, R. "Impact of technological progress and efficiency changes on the productivity growth of Iran agriculture sector: Data envelopment analysis", Quartery Journal of Economical Modeling, 10(34), pp. 133-148 (2016).

36. Sadeghi, S.R., Maleki, M.H., and Motaghi, P. "A twostage dynamic model for evaluating the performance of private banks: Using DEA approach", Journal of Monetary and Banking Research, 4(35), pp. 83-98 (2018).

37. Fujii, H., Managi, S., Matousek, R., et al. "Bank efficiency, productivity, and convergence in EU countries: a weighted Russell directional distance model", The European Journal of Finance, 24(2), pp. 135-156 (2018).

38. Kao, C. and Liu, S-T. "Stochastic data envelopment analysis in measuring the efficiency of Taiwan commercial banks", European Journal of Operational Research, 196(1), pp. 312-322 (2009).

39. Charnes, A. and Cooper, W.W. "Programming with linear fractional functionals", Naval Research Logistics Quarterly, 9(3-4), pp. 181-186 (1962).

40. Wang, K., Huang, W., Wu, J., et al. "Efficiency measures of the Chinese commercial banking system using an additive two-stage DEA", Omega, 44, pp. 520 (2014).

41. Wanke, P. Barros, C.P., and Emrouznejad, A. "Assessing productive efficiency of banks using integrated Fuzzy-DEA and bootstrapping: A case of Mozambican banks", European Journal of Operational Research, 249(1), pp. 378-389 (2016).
42. Yang, C. and Liu, H-M. "Managerial efficiency in Taiwan bank branches: A network DEA", Economic Modelling, 29(2), pp. 450-461 (2012).

43. Giokas, D.I. "Assessing the efficiency in operations of a large Greek bank branch network adopting different economic behaviors", Economic Modelling, 25(3), pp. 559-574 (2008).

44. LaPlante, A.E. and Paradi, J.C. "Evaluation of bank branch growth potential using data envelopment analysis", Omega, 52, pp. 33-41 (2015).

45. Ray, S. "Cost efficiency in an Indian bank branch network: A centralized resource allocation model", Omega, 65, pp. 69-81 (2016).

46. Jahangir Nia, H. and Esfandiar, M. "Assessment of the efficiency of banks accepted in Tehran stock exchange using the data envelopment analysis technique", Journal of Industrial Strategic Management, 2(3), pp. 1-7 (2018).

47. Wanke, P. Maredza, A., and Gupta, R. "Merger and acquisitions in South African banking: a network DEA model", Research in International Business and Finance, 41, pp. 362-376 (2017).

48. Zarei Mahmoudabadi, M. "Multilevel measuring of efficiency in banking industry (Network Slacks-Based Measure (NSBM) Approach)", Journal of Industrial Management, 8(3), pp. 359-380 (2016).

49. Cook, W.D. and Seiford, L.M. "Data envelopment analysis (DEA)-Thirty years on", European Journal of Operational Research, 192(1), pp. 1-17 (2009).

\section{Biographies}

Jafar Esmaeeli is a PhD student at the Department of Industrial Management, Faculty of Management and Economics and Accounting, Islamic Azad University, Tabriz Branch, Iran. His areas of interest include DEA, productivity, and multi-criteria decision-making.

Maghsoud Amiri received his MS and PhD degrees in Industrial Engineering from Sharif University of Technology, Tehran, Iran. He is currently a Professor at the Industrial Management Department, Faculty of Management and Accounting, Allameh Tabataba'i University, Tehran, Iran. His research interests include supply chain management and multiple-criteria decision-making.

Houshang Taghizadeh is currently a Professor at the Department of Industrial Management, Faculty of Management and Economics and Accounting, Islamic Azad University, Tabriz Branch, Iran. His area of research is production management. 